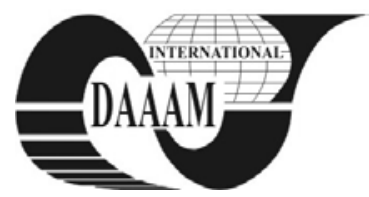

\title{
DENTAL IMPLANTS MECHANICAL PROPERTIES: FEA VS. PHYSICAL TESTING
}

\author{
DUSE, D[an] - M[aniu] \& PASA, A[lexandru]
}

\begin{abstract}
The current study aims at determining the accuracy of finite element analysis investigations, in the field of dental implants, by comparing their results to the corresponding physical tests. Two of the most representative implant systems on the market were selected for the comparison. The chosen implants are made of Grade 4, respectively Grade 5 titanium. The FEA results differ from the physical testing results for one of the systems, and partially match the other.

Key words: fatigue, dental, implant, FEA, comparison
\end{abstract}

\section{INTRODUCTION}

Dental implant design does not have a specific set of rules (Duse \& Pasa, 2010). Since the calculation capabilities improved, the finite element method has been introduced in the design process, in order to optimize the implant's geometry and material. In the last years researchers tried to develop some dental implants design guide lines using FEA (Ao et al., 2010), (Baggi et al., 2008), (Hansson \& Werke, 2003), (Kong et al., 2009). In order to determine the accurateness of the finite element method results, we acquired finite element analysis, made according to ISO 14801:2007, for two dental implant systems, with replica abutments and screws. The reported values were checked by physical testing, according to the same standard.

\section{MATERIALS AND METHODS}

For the tests, both FEA and physical, the replica abutments and abutment fixing screws, came from the same manufacturer. These parts are made from the same material as the original systems' ones: Ti Grade5. The FEA testing reports, made according to ISO 14801:2007, were considered the input data and starting point for the physical tests. The implant systems used in the study are presented in Fig. 1. They will be further named System A and System B.

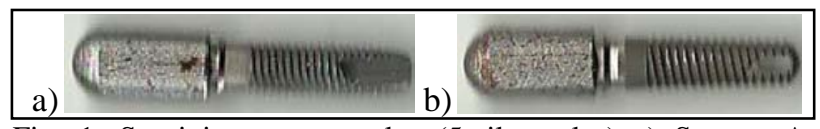

Fig. 1. Surviving test samples (5mil. cycles) a) System A; b) System B

The installations used for the testing are: Hounsfield H10KT, for the static testing, and Instron 8872, for the fatigue testing. The tests' loading setup can be observed in Fig. 2. The tested parts are identical to the FEA models and their specifications are presented in Tab. 1 .

The measurements which insured the correct mounting of the implants and abutments were made with a calliper, with a measuring error of $0,01 \mathrm{~mm}$, according to DIN 862 (Fig. 3). The testing environment temperature was $22^{\circ} \mathrm{C}$.

The loading members, specimen holder and loading device are made of steel with an elastic modulus of 200GPa. The loading members were press-fitted onto the abutments.
The first step of the tests was to determine the static breaking load of the systems, by applying a displacement of $1 \mathrm{~mm} / \mathrm{min}$ to the loading device until the tested specimen broke, according to SR EN ISO 6892-2010 and ISO 14801:2007. Next, the implants were subjected to fatigue testing, as advised by the ISO 14801:2007 standard, using the FEA results as guidelines, until the fatigue limit for each of them was confirmed - 3 specimens endured the fatigue limit load for 5 mil. cycles. The fatigue testing frequency was $15 \mathrm{~Hz}$.

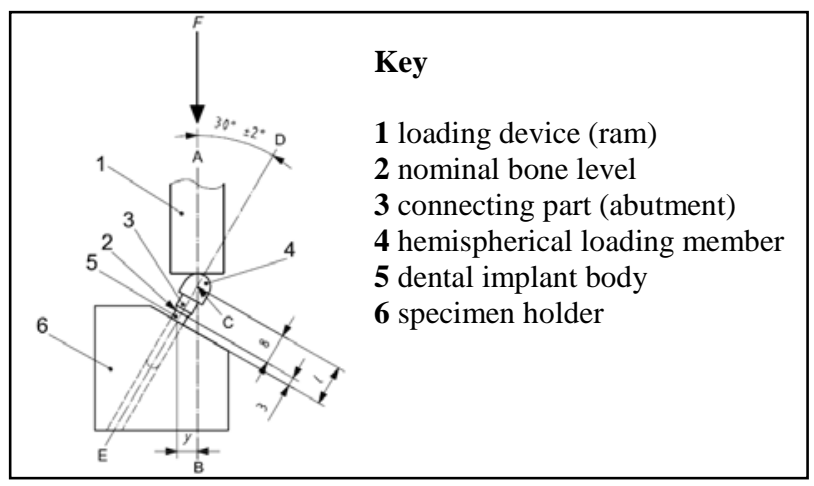

Fig. 2. Testing set-up schematics for systems with no pre angled connecting parts, according to ISO 14801:2007

\begin{tabular}{|c|c|c|c|c|c|}
\hline $\begin{array}{c}\text { Implant } \\
\text { System }\end{array}$ & $\begin{array}{c}\text { Implant } \\
\text { material }\end{array}$ & $\begin{array}{c}\text { Implant } \\
\text { diameter } \\
\text { [mm] }\end{array}$ & $\begin{array}{c}\text { Implant } \\
\text { length } \\
\text { [mm] }\end{array}$ & $\begin{array}{c}\text { Abutment } \\
\text { material }\end{array}$ & $\begin{array}{c}\text { Abutment } \\
\text { screw } \\
\text { torque } \\
\text { [Ncm] }\end{array}$ \\
\hline System A & $\begin{array}{c}\text { Ti Grade4 } \\
\text { CP }\end{array}$ & 3,5 & 13 & $\begin{array}{c}\text { Ti Grade5 } \\
\text { CP }\end{array}$ & 35 \\
\hline System B & $\begin{array}{c}\text { Ti Grade5 } \\
\text { CP }\end{array}$ & 3,7 & 13 & $\begin{array}{c}\text { Ti Grade5 } \\
\text { CP }\end{array}$ & 30 \\
\hline
\end{tabular}

Tab. 1. Tested samples specifications

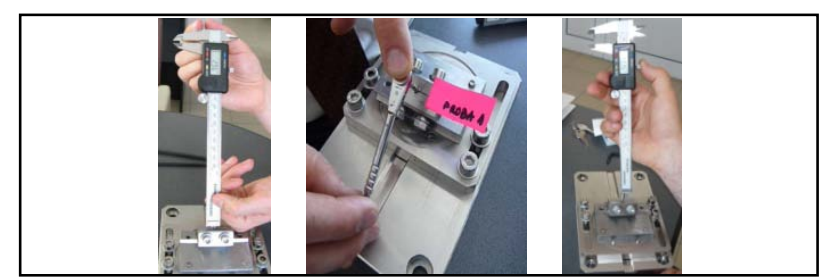

Fig. 3. Implant specimen holder and samples mounting process

\section{RESULTS}

\subsection{Static tests results}

The static tests results are presented in Tab. 2.

\begin{tabular}{|l|c|c|}
\hline System & System A & System B \\
\hline FEA static load to failure & $534 \mathrm{~N}$ & $613 \mathrm{~N}$ \\
\hline Physical static load to failure & $492.5 \mathrm{~N}$ & $675 \mathrm{~N}$ \\
\hline
\end{tabular}

Tab. 2. Static results - FEA vs. Physical 


\subsection{Fatigue tests results}

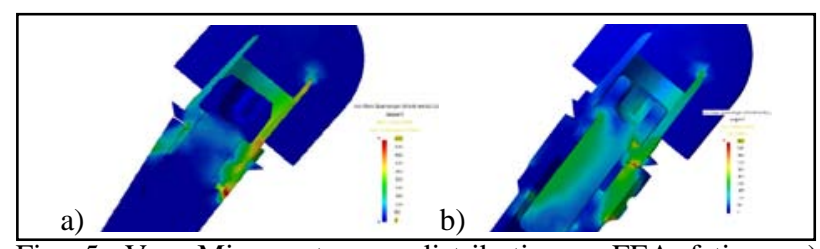

Fig. 5. Von Misses stresses distribution - FEA fatigue a) System A; b) System B

The System A implants came from two different batches. The mechanical resistance of the two greatly differed, as it can be seen in Fig. 6. The fatigue limit physically determined is $240 \mathrm{~N}$ and does not match the FEA result of 332N.

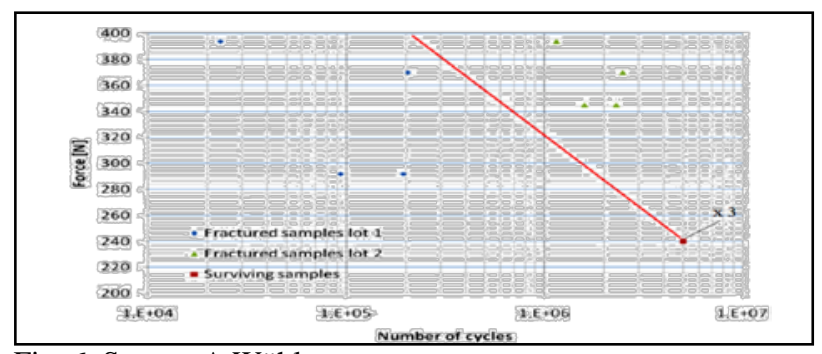

Fig. 6. System A Wöhler curve

The System B implants came from three different batches. All three batches proved similar mechanical resistance, as it can be seen in Fig. 7. The FEA fatigue limit of $337 \mathrm{~N}$ was confirmed by the physical testing.

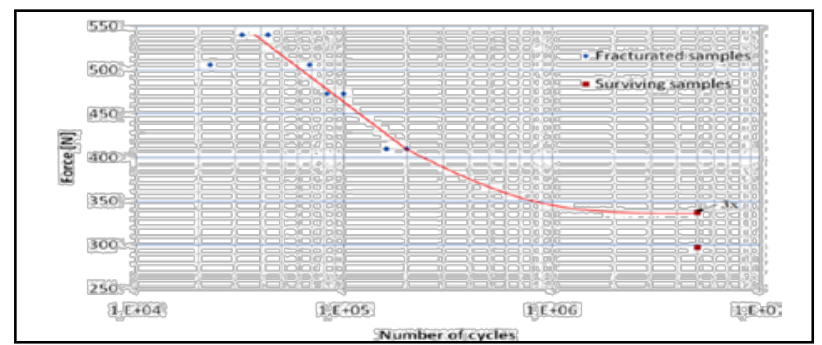

Fig. 7. System B Wöhler curve

\section{CONCLUSIONS}

During the tests, the implant bodies were the ones that broke, either at the specimen holder level, or at the implant collar level-Fig. 8 (abutments remained intact). This behaviour of the tested samples matches the FEA investigations results.

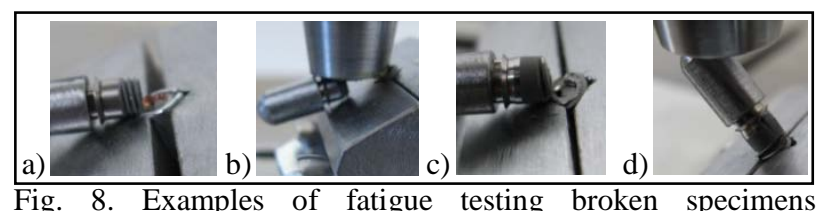

a), b) System A; c), d) System B

From the location of the high stressed areas point of view, the FEAs were mostly consistent with the physical tests. However, from the load and stress values point of view, the FEAs were mostly inconsistent with the physical tests results (Tab. 3). Based on the authors' experience in the field of engineering, a few factors that might determine such differences in the output data are listed below:

1. Regarding the developer: not enough specifications in the part/assembly drawings;

2. Regarding the manufacturer: fluctuations of the implant's manufacturing process; flaws in the quality management system;
3. Regarding the FEA engineer: incorrect representation of the real world event; insufficient mesh density to properly capture the solution; the usage of too high compensation energies;

4. Regarding the physical testing technician: testing samples mishandling; not respecting the manufacturer's abutment mounting specifications; testing parameters/equipment not in compliance with the testing standards requirements.

Based on the current results, we conclude that FEA is an approximating analysis tool and that its results should be double checked by physical testing, before being implemented into production.

\begin{tabular}{|c|c|c|c|c|c|c|}
\hline $\begin{array}{c}\text { Tested } \\
\text { Implant } \\
\text { system }\end{array}$ & $\begin{array}{l}\text { FEA } \\
\text { max. } \\
\text { static } \\
\text { load } \\
{[\mathrm{N}]} \\
\end{array}$ & $\begin{array}{c}\text { Physical } \\
\text { max. } \\
\text { static load } \\
{[\mathrm{N}]}\end{array}$ & $\begin{array}{c}\text { FEA } \\
\text { fatigue } \\
\text { limit } \\
\text { load } \\
{[\mathrm{N}]}\end{array}$ & \begin{tabular}{|c|} 
Physical \\
fatigue \\
limit load \\
{$[\mathrm{N}]$}
\end{tabular} & \begin{tabular}{|c}
$F_{\text {static }}$ \\
$F_{\text {fatigue }}$ \\
FEA \\
{$[\%]$}
\end{tabular} & 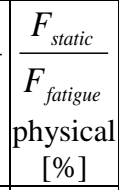 \\
\hline & 534 & 492 , & 332 & 240 & 62,17 & 48,73 \\
\hline System & 613 & 675 & 337 & 337 & 54,98 & 49,93 \\
\hline
\end{tabular}

Tab. 3. Analyses results comparison

One partial conclusion that could also be drawn, based on the current tests results (Tab. 3), is that the fatigue limit load is about $50 \%$ of the static breaking load, for screw shaped rigid assembly implant systems, made of Grade4 and Grade5 titanium, tested according to ISO 1480:2007. Further investigations are necessary on other implant systems, in order to generalize this result.

\section{ACKNOWLEDGEMENTS}

We would like to thank NT-Trading GmbH for their support, funding and materials, without which these tests would not have been possible.

Research developed within the POSDRU/6/1.5/S/26 project, co-financed by The Development of Human Resources Sectorial Operational Program 2007-2013, from the European Social Fund.

Tests developed within the Lucian Blaga University, Sibiu, Romania PhD. programs, at the INCDMTM institute, Bucharest, Romania.

\section{REFERENCES}

Ao, J.; Li, T.; Liu, Y.; Ding, Y.; Wu, G.; Hua, K. \& Kong, K. (2010). Optimal design of thread height and width on an immediately loaded cylinder implant: A finite element analysis. Computers in Biology and Medicine, Vol. 40, No. 8, (August 2010) pp. 681-686, ISSN: 0010-4825

Baggi, L.; Cappelloni, I; Di Girolamo, M.; Maceri, F. \& Vairo, G. (2008). The influence of implant diameter and length on stress distribution of osseointegrated implants related to crestal bone geometry: A three-dimensional finite element analysis. The Journal of Prosthetic Dentistry, Vol. 100, No. 6, (December 2008) pp. 422-431, ISSN: 0022-3913

Hansson, S. \& Werke, M. (2003). The implant thread as a retention element in cortical bone: the effect of thread size and thread profile: a finite element study. Journal of Biomechanics, Vol. 36, No. 9, (September 2003) pp. 12471258, ISSN: 0021-9290

Duse, DM. \& Pasa, A. (2010), Screw shaped dental implants analysis tool. Academic Journal of Manufacturing Engineering, Vol.8, No. 2, (April 2010) pp. 32-38, ISSN: 1583-7904

Kong, L.; Zhao, Y.; Hua, K.; Li, D.; Zhou, H.; Wuc, Z. \& Liu, B. (2009). Selection of the implant thread pitch for optimal biomechanical properties: A three-dimensional finite element analysis. Advances in Engineering Software, Vol. 40, No. 7, (July 2009) pp. 474-478, ISSN: 0965-9978 